\title{
Changing trends of ocular trauma in the time of COVID-19 pandemic
}

\author{
Marco Pellegrini (i) ${ }^{1} \cdot$ Matilde Roda $^{1} \cdot$ Natalie Di Geronimo ${ }^{1} \cdot$ Enrico Lupardi $^{1} \cdot$ Giuseppe Giannaccare $^{2}$. \\ Costantino Schiavi ${ }^{1}$
}

Received: 11 April 2020 / Revised: 23 April 2020 / Accepted: 24 April 2020 / Published online: 6 May 2020

(c) The Royal College of Ophthalmologists 2020

\section{To the Editor:}

To reduce the spread of the novel coronavirus (2019$\mathrm{nCoV}$ ), countries have promoted a range of unprecedented public health responses. These measures aim at reducing the final size of the epidemic as well as its peak in order to decrease the acute pressure on the health-care system [1]. In Italy, the government ordered people to stay home, restricting movements with the exception of work, urgent matters and health reasons. Furthermore, all commercial and productive activities, except those providing essential services, were obligated to remain closed [2].

Ocular trauma represents a serious public health problem and leading cause of visual impairment [3, 4]. The COVID19 social distancing measures might have a significant impact on the risk of ocular trauma. In this study, we retrospectively reviewed the charts of all patients presenting to an Italian ophthalmological emergency department (the Ophthalmology Unit of the S.Orsola-Malpighi University Hospital in Bologna) to identify all eye injuries. Data were analysed from 10th March 2020 (i.e. the day in which the quarantine measures were applied in our city) to 10th April 2020, and confronted with those of the same period of the previous year (from 10th March 2019 to 10th April 2019).

In the 2019 study period, there were 354 eye injuries (15.6\% of all patients presenting to the emergency department). In the 2020 study period, eye injuries decreased to 112 (19.9\% of all patients). The characteristics of eye injuries in the two study periods are reported in Table 1 . During quarantine, the proportion of children and

Marco Pellegrini

marco.pellegrini@hotmail.it

1 Ophthalmology Unit, S.Orsola-Malpighi University Hospital, University of Bologna, Bologna, Italy

2 Department of Ophthalmology, University of "Magna Graecia", Catanzaro, Italy
Table 1 Characteristics of eye injuries in the 2019 study period (from 10th March 2019 to 10th April, 2019) and 2020 study period (from 10th March 2020 to 10th April 2020).

\begin{tabular}{|c|c|c|}
\hline Characteristic & 2019 period & 2020 period \\
\hline Total number of eye injuries & 354 & 112 \\
\hline $\operatorname{Sex}(\mathrm{m} / \mathrm{f})$ & $236 / 109$ & $84 / 28$ \\
\hline Mean age $( \pm \mathrm{SD})$ & $40.7 \pm 19.7$ & $43.3 \pm 17.4$ \\
\hline \multicolumn{3}{|c|}{ Mechanism of injury ( $\%$ of the total) } \\
\hline Sports & $21(5.9 \%)$ & $3(2.7 \%)$ \\
\hline Manual works $^{\mathrm{a}}$ & $49(13.8 \%)$ & $18(16.1 \%)$ \\
\hline Animal care & $8(2.3 \%)$ & $4(3.6 \%)$ \\
\hline Gardening/injuries with plants & $30(8.5 \%)$ & $12(10.7 \%)$ \\
\hline Home activities & $44(12.4 \%)$ & $19(17.0 \%)$ \\
\hline Falls & $23(6.5 \%)$ & $1(0.9 \%)$ \\
\hline Burns/corrosive substances & $26(7.3 \%)$ & $8(7.1 \%)$ \\
\hline Violence & $15(4.2 \%)$ & $6(5.4 \%)$ \\
\hline Other/unknown & $138(39.0 \%)$ & $41(36.6 \%)$ \\
\hline \multicolumn{3}{|l|}{ Diagnosis (\% of the total) } \\
\hline None & $33(9.3 \%)$ & $1(0.9 \%)$ \\
\hline Foreign body on external eye & $142(40.1 \%)$ & $56(50.0 \%)$ \\
\hline $\begin{array}{l}\text { Superficial injury (cornea and } \\
\text { conjunctiva) }\end{array}$ & $97(27.4 \%)$ & $39(34.8 \%)$ \\
\hline Subconjunctival haemorrhage & $23(6.5 \%)$ & $6(5.4 \%)$ \\
\hline Eyelid injury & $33(9.3 \%)$ & $3(2.7 \%)$ \\
\hline Posterior vitreous detachment & $2(0.6 \%)$ & $1(0.9 \%)$ \\
\hline Hyphema & $4(1.1 \%)$ & $4(3.6 \%)$ \\
\hline Retinal oedema & $15(4.2 \%)$ & $1(0.9 \%)$ \\
\hline Vitreous haemorrhage & $1(0.3 \%)$ & $0(0.0 \%)$ \\
\hline Orbital fracture & $3(0.8 \%)$ & $0(0.0 \%)$ \\
\hline Penetrating wound & $1(0.3 \%)$ & $1(0.9 \%)$ \\
\hline
\end{tabular}

${ }^{\mathrm{a}}$ Grinding, cutting, sanding, drilling, hammering, sawing.

adolescents with eye injuries decreased (from $14.7 \%$ to $8.0 \%$, Fig. 1a), while the proportion of males increased (from $66.7 \%$ to $75.0 \%$, Fig. 1b). Regarding the mechanisms of injury, the percentage of falls and sport injuries had the 

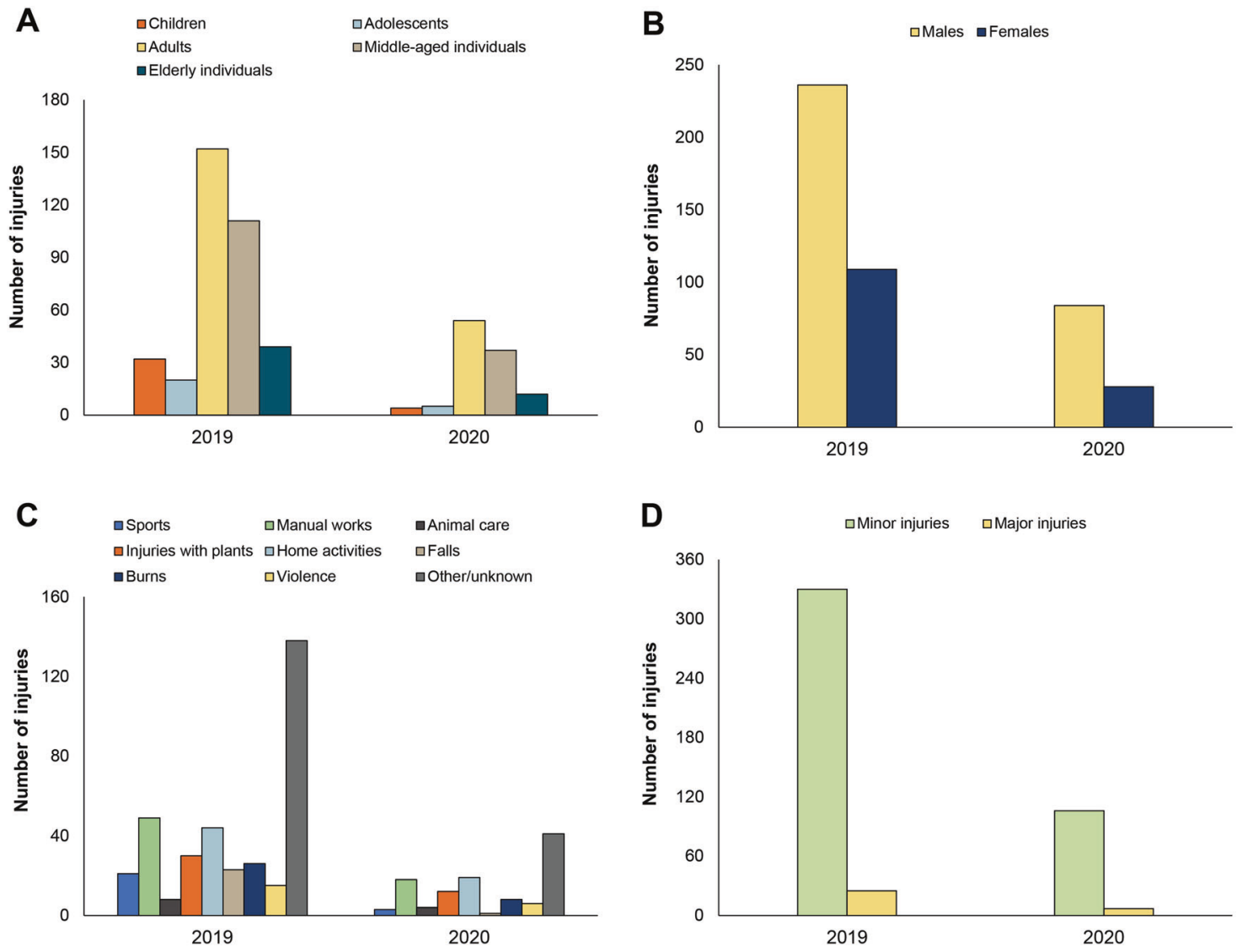

Fig. 1 Number of eye injuries in the 2019 study period (from 10th March 2019 to 10th April, 2019) and 2020 study period (from 10th March 2020 to 10th April 2020). (a) Eye injuries categorized by age.

(b) Eye injuries categorized by sex. (c) Eye injuries categorized by mechanism of trauma. (d) Eye injuries categorized as minor or major injuries.

highest decrease (respectively, from $6.5 \%$ to $0.9 \%$ and from $5.9 \%$ to $2.7 \%$ ), while injuries during home activities and injuries with plants had the highest increase (respectively, from $12.4 \%$ to $17.0 \%$ and from $8.5 \%$ to $10.7 \%$, Fig. 1c). The percentage of minor injuries with low risk of vision loss increased (from $93.2 \%$ to $94.6 \%$ ), while major injuries requiring monitoring decreased (from $6.8 \%$ to $5.4 \%$, Fig. 1d).

There was a striking $68.4 \%$ decrease in the number of eye injuries seen in our Unit during the last month. Behavioural changes during the quarantine could be associated with lower risk of trauma. The decreases of sport injuries and of injuries in children during school closure seem to support this hypothesis. However, the drop of patients seeking emergency care affected all injuries, including serious ones potentially associated with vision loss. We believe that some patients may intentionally avoid urgent care rather than risking coronavirus exposure at hospitals. Anecdotal reports suggest that this is also happening for life-threatening medical emergencies such as myocardial infarction and stroke [5, 6]. Since ocular trauma is a major cause of vision loss, the importance of not delaying or

avoiding treatment should be stressed to all patients to prevent ocular morbidities.

\section{Compliance with ethical standards}

Conflict of interest The authors declare that they have no conflict of interest.

Publisher's note Springer Nature remains neutral with regard to jurisdictional claims in published maps and institutional affiliations.

\section{References}

1. Wilder-Smith A, Chiew CJ, Lee VJ. Can we contain the COVID-19 outbreak with the same measures as for SARS?. Lancet Infect Dis. 2020. https://doi.org/10.1016/S1473-3099(20)30129-8.

2. Italian Government. decreto del presidente del Consiglio dei ministri (DPCM) March 11, 2020. http://www.governo.it/it/articolo/ coronavirus-conte-firma-il-dpcm-11-marzo-2020/14299.

3. Matsa E, Shi J, Wheeler KK, McCarthy T, McGregor ML, Leonard JC. Trends in US emergency department visits for pediatric acute ocular injury. JAMA Ophthalmol. 2018;136:895-903.

4. Négrel AD, Thylefors B. The global impact of eye injuries. Ophthalmic Epidemiol. 1998;5:143-69. 
5. Krumholz HM. Where have all the heart attacks gone? New York Times; 2020. https://www.nytimes.com/2020/04/06/well/live/corona virus-doctors-hospitals-emergency-care-heart-attack-stroke.html.
6. American Hearth Association. Health emergency? Don't hesitate to get help. 2020. https://www.heart.org/en/news/2020/03/30/healthemergency-dont-hesitate-to-get-help. 